\title{
CÂNONE E EXCLUSÃO
}

Kelvin Falcão Klein*

\author{
*kelvin.klein@gmail.com \\ Doutor em Teoria Literária pela Universidade Federal \\ de Santa Catarina (UFSC). Mestre em Literatura \\ Comparada pela Universidade Federal do Rio Grande \\ do Sul (UFRGS).
}

RESUMO: O texto propõe uma reflexão sobre o cânone na teoria literária e na literatura comparada, tendo como norte uma aproximação com a noção de exclusão e uma elaboração dos conceitos de "hipercânone" contracânone", cunhados por David Damrosch em ensaio de 2006.

ABSTRACT: The present text proposes a reflection about the canon, in literary theory and comparative literature, having as its main goal an approximation to the notion of exclusion and an elaboration of the concepts of "hypercanon" and "countercanon", proposed by David Damrosch in a 2006 essay.

PALAVRAS-CHAVE: Cânone; Exclusão; Teoria Literária.

KEYWORDS: Canon; Exclusion; Literary Theory. 
1. GINZBURG. "O valor estético: entre universalidade e exclusão", p. 105-106.
No que diz respeito ao cenário acadêmico brasileiro, Jaime Ginzburg oferece um panorama sobre as questões do cânone e do valor estético em um ensaio de 2008, intitulado "O valor estético: entre universalidade e exclusão". Analisando sobretudo trabalhos surgidos ao longo da década de 1990, como os de Nelly Richard, Beatriz Sarlo e Eduardo Coutinho, Ginzburg nota uma tendência bastante acentuada de recusa a posições essencialistas na concepção do cânone e de seus critérios, como é o caso, segundo Ginzburg, de Harold Bloom e seu estudo sintomaticamente intitulado $O$ cânone ocidental, publicado originalmente em 1994. Durante muito tempo, a discussão teórica sobre a formação do cânone negligenciou a historicidade dos critérios utilizados. Em resposta a isso, afirma Ginzburg, a feição contemporânea do debate sobre o cânone agrega também a dimensão da exclusão, ou seja, os traços de violência inerentes a todo gesto de escolha e seleção estética ${ }^{1}$. A ligação do tema do cânone literário às repercussões amplas dos estudos pós-coloniais, sobretudo no que diz respeito à dimensão geopolítica da circulação dos textos literários, faz com que uma discussão sobre as estratégias de composição canônica seja também uma discussão sobre a potencial violência inerente a essas estratégias.

Em 2001, um pouco antes da publicação do texto de Jaime Ginzburg, a Associação Brasileira de Literatura Comparada (ABRALIC) promoveu um Colóquio na Universidade
Federal de Minas Gerais, com o intuito de discutir o tema "Valores: Arte, Mercado, Política". No âmbito do encontro, Andreas Huyssen apresenta um ensaio intitulado "Literatura e cultura no contexto global”. Assim como na exposição de Jaime Ginzburg, Huyssen tem o cuidado de frisar que não há consenso no que diz respeito não apenas à formação do cânone, mas à própria validade e circulação da ideia de valor estético para se pensar a cultura contemporânea. Na perspectiva de Huyssen, o ponto fundamental da discussão sobre o cânone nos estudos literários reside na diferenciação entre as táticas de abertura e emancipação dos critérios de formação do cânone e o estabelecimento de estratégias programáticas no campo da teoria literária. "Em uma época em que se espera dos estudos literários que cubram cada vez mais território, geográfica e historicamente, sobrecarregando, assim, os circuitos de qualquer crítico", escreve Huyssen, "o perigo é a disciplina perder sua coerência como campo de pesquisa, atolar-se em estudos de casos locais ou tornar-se superficial, negligenciando a necessidade de manter um projeto metodológico e teórico"

No que diz respeito ao cânone e a exclusão, é delicado o caminho que leva da marcação de casos, representativos da exclusão e da negligência por parte da teoria clássica, e o retorno dessa marcação a uma abordagem mais especulativa, interessada em constituir as bases metodológicas dos estudos
2. HUYSSEN. “Literatura e cultura no contexto global", p. 18.

$\begin{array}{llllll}\text { EM TESE } & \text { BELO HORIZONTE } & \text { v. } 19 & \text { N. } 2 & \text { AG0.-0ut. } 2013 & \text { KLEIN. Cânone e exclusão }\end{array}$

\section{Ensino e teoria}


literários. Huyssen aponta uma espécie de dilema que surge do exercício continuado de revisão do cânone, tal como praticado pelos estudos culturais de extração norte-americana. Na marcação progressiva de diferentes possibilidades de representação dentro do cânone, cujos exemplos mais claros dizem respeito às reivindicações dos estudos de gênero e os estudos pós-coloniais, Huyssen enxerga uma diluição da atividade teórica e metodológica. Essa diluição, ligada ao isolacionismo inerente aos variados programas de reivindicação canônica, leva a uma simples inversão dos termos do debate sobre valor estético e formação do cânone. A clausura da percepção, tão criticada nos modelos de educação literária da primeira metade do século $\mathrm{XX}$, permanece mais ou menos a mesma, somente camuflada pela multiplicidade de reivindicações em circulação e com os sinais de valor invertidos.

"O modelo norte-americano de estudos culturais", resume Huyssen, "com seu foco reducionista em temática e etnografias culturais, seu privilegiar mais o consumo do que produção, sua falta de profundidade histórica", além de "seu abandono de questões estéticas e formais conjugados ao seu privilegiar sem questionar a cultura de massa e popular, não é um modelo adequado para enfrentar novos desafios"3. Essa passagem mostra que Huyssen, longe de corroborar uma posição como aquela de Harold Bloom, já criticada por Jaime Ginzburg, ainda assim consegue enxergar as limitações da versão norte-americana dos estudos culturais, que remetem precisamente ao excesso na multiplicação de esferas representativas no âmbito do pensamento e o pouco esforço de delimitação de bases metodológicas. A delimitação do campo de atuação é complexa, pois a solução não está nem na declaração de Bloom, de simplesmente rechaçar essas práticas da representatividade como a "escola do ressentimento" ${ }^{4}$, ou em chancelá-las sem revisão. É essa revisão crítica que Huyssen propõe em seu ensaio, propondo também um desvio do impasse, resgatando os esforços de abertura do cânone em suas representatividades históricas, mas frisando que o trabalho, daqui para a frente, deve ser distinto.

Em outras palavras, é possível dizer que cânone é e sempre será sinônimo de exclusão, e que é a partir da consciência dessa equivalência - uma equivalência que indica não um estado de repouso, mas uma situação de confronto permanente entre os dois termos - que pode emergir um trabalho teórico que não se contente apenas com a substituição ou reposicionamento dos elementos constituintes dos cânones Tal trabalho teórico tomaria como norte os aspectos historicamente situados de todo gesto de substituição e reposicionamento, o que levaria a uma concepção horizontalizada de conceitos como os de valor estético, cânone e exclusão, sem a verticalização hierarquizante que a lógica da substituição pressupõe.
4. BLOOM. $O$ cânone ocidental: os livros e a escola do tempo, p. 58.
EM TESE
BELO HORIZONTE
v. 19
N. 2
AG0.-OUT. 2013
KLEIN. Cânone e exclusão
P. $111-12$

\section{Ensino e teoria}


5. CHOW. "In the Name of Comparative Literature", p. 109. Gayatri Chakravorty Spivak, ainda que sua abordagem diga respeito mais à política ocidental do que à literatura ocidental, ataca o mesmo problema quando escreve: "Algumas das críticas mais radicais produzidas pelo Ocidente hoje são o resultado de um desejo interessado em manter o sujeito do Ocidente, ou o Ocidente como Sujeito. A teoria dos 'sujeitos-efeitos' pluralizados dá a ilusão de um abalo na soberania subjetiva, quando, muitas vezes, proporciona apenas uma camuflagem para esse sujeito do conhecimento" Cf. SPIVAK. Pode o subalterno falar?, p. 20-21.
Nesse sentido, é importante resgatar as palavras da pesquisadora Rey Chow, no ensaio que publicou no volume coletivo Literatura Comparada na era do multiculturalismo, de 1994. Segundo Chow, o problema da constituição do cânone não desaparece se simplesmente substituirmos Inglaterra, França e Alemanha por Índia, China ou Japão. Nessa perspectiva, o conceito de literatura, afirma Chow, fica restrito a uma concepção darwinista do valor e da circulação cultural ${ }^{5}$. A reflexão crítica sobre o cânone, portanto, não deve investir nem na substituição pura e simples (a China no lugar da Inglaterra), nem na soma desprovida de critério (China e Inglaterra e todo o resto), mas em uma manobra interpretativa que considere a multiplicidade não como um valor em si, mas como um dos elementos disponíveis para a problematização do cânone. Não se trata de abandonar a leitura de Shakespeare, substituindo-o por qualquer outro autor negligenciado pela história oficial da literatura, mas sim de ler Shakespeare a partir de novas perspectivas, refundando a tradição e restabelecendo o cânone a partir de novas bases.

Eis aqui um exemplo de como o cânone é, de fato, exclusão, mas não só a exclusão teleológica implícita no gesto de substituição, mas também uma exclusão que é, até certo ponto, criativa e criadora. Exclui-se do cânone não a presença da obra arquiconhecida, mas a sedimentação viciada dos caminhos que levam a ela. É precisamente essa a natureza do comentário de Jonathan Culler, em seu manual de teoria literária de 1999, quando reflete sobre os projetos de abertura e emancipação dos critérios de formação do cânone. "Nunca se escreveu tanto sobre Shakespeare", escreve Culler, "ele é estudado de todos os ângulos concebíveis, interpretado nos vocabulários feminista, marxista, psicanalítico, historicista e desconstrucionista"6. Não se trata de uma posição hegemônica, pois, como vimos na perspectiva de Andreas Huyssen, boa parte dos esforços dos estudos culturais norte-americanos envolve a postura da substituição. Porém, tendo presente esse diagnóstico dado por Huyssen, fica mais evidente e produtivo o corte proposto tanto por Rey Chow quanto por Jonathan Culler. Chow apresenta uma visão do cânone que não é pautada nem pela substituição nem pela agregação, mas pela problematização do gesto que leva à decisão de um ou de outro - mostrando que, mesmo que aparentemente distantes, os procedimentos de substituição e de agregação reforçam o mesmo essencialismo. E Culler, por sua vez, exemplifica a produtividade criativa da exclusão, quando ela resulta em clivagens que iluminam aquilo que há de diferença na repetição.

É preciso recapitular o percurso até aqui, para melhor observar as ligações entre as várias etapas. Em primeiro lugar, a exposição de Jaime Ginzburg, feita a partir de ensaios da década de 1990 dedicados à articulação do valor estético em
6. CULLER. Teoria Literária: uma introdução, p. 53.

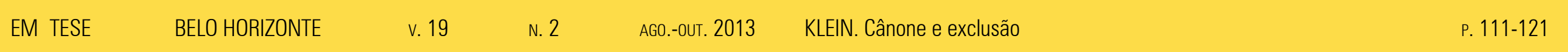

\section{Ensino e teoria}


literatura com a política da memória, posicionava a discussão sobre o cânone em um cenário de questionamento da violência inerente às premissas de constituição desse mesmo cânone. Tendo em vista o diagnóstico da violência na constituição do cânone, mas procurando especificar o debate em direção a uma teoria que resolvesse os impasses das múltiplas representatividades, Andreas Huyssen postula uma percepção horizontal do debate, que permite a transposição das dicotomias que regem a lógica da substituição no que diz respeito ao cânone. O ensaio de Rey Chow reforça a necessidade de se buscar modelos teóricos e metodológicos que escapem da lógica da substituição, insistindo nas potencialidades oferecidas pelo cenário de emancipação do cânone. Ainda que incidentalmente, Jonathan Culler oferece uma perspectiva prática do assunto, argumentando que, por vezes, a exclusão no cânone diz respeito mais a procedimentos de análise do que à seleção de obras e autores - sem que isso redunde, necessariamente, em ganhos práticos no que diz respeito ao trabalho crítico.

Não se trata, porém, de uma progressão pura e simples, na qual as diferentes etapas, tal como apresentadas acima, se sucedem pacificamente num dado período histórico. Muito pelo contrário, a exposição progressiva é apenas didática, e deve ser acompanhada da ressalva de que essas etapas estão sobrepostas e entram em confronto umas com as outras.

Essas variadas considerações teóricas a respeito do cânone acabam por espelhar, até certo ponto, as próprias características do objeto em questão: o cânone é, fundamentalmente, uma espécie de estrutura cognitiva imaterial que não opera a partir de progressões puras e simples, e sim a partir de idas e vindas concomitantes, seja no tempo ou no espaço. $\mathrm{O}$ trabalho teórico em torno do cânone e de suas estratégias de constituição, portanto, é, em grande medida, estimulado por esse caráter errático típico do objeto.

Como exemplo dessa movimentação, poderíamos lembrar a obra do Marquês de Sade, evocado por Eliane Robert Moraes em ensaio intitulado "Os perigos da literatura: o 'caso Sade”. Deliberadamente negligenciada por mais de cem anos, a obra do Marquês de Sade começa a ser reeditada, na França, em 1947. O editor responsável, Jean-Jacques Pauvert, é chamado pela justiça francesa alguns anos depois para responder a um processo de atentado à moral. Eliane Robert Moraes aponta que figuras proeminentes do cenário intelectual francês da época foram chamadas para a defesa de Pauvert, tais como André Breton, Jean Cocteau, Jean Paulhan e Georges Bataille, o que redundou na absolvição do editor e na liberação da edição das obras de Sade ${ }^{7}$.

No que diz respeito ao pensamento francês da segunda metade do século XX, a presença de Sade foi fundamental. Não é possível determinar em que medida o Marquês
7. MORAES. "Os perigos da literatura: o 'caso Sade'"', p. 150

\section{Ensino e teoria}


estimulou a criação de conceitos e tópicos de pesquisa ou se, de forma inversa, foi sua obra que surgiu como historicamente adequada às teorias que então surgiam. $\mathrm{O}$ fato é que a obra de Sade, depois de décadas de esquecimento, foi alçada à condição de peça fundamental na teorização de, entre outros, Georges Bataille, Michel Foucault, Maurice Blanchot, Jacques Derrida e Roland Barthes. Essa atualização sadiana por parte do pensamento francês trata, fundamentalmente, da oscilação entre a constituição canônica e suas estratégias de exclusão. Isso porque o resgate crítico de Sade não celebra seu retorno, mas faz desse retorno uma oportunidade para discutir as estratégias de recalque que incidiram, durante muito tempo, sobre essa obra. Ainda que a obra de Sade esteja, até certo ponto, sendo inserida no cânone, o pensamento crítico que se ocupa dessa obra entende que o histórico de exclusão também faz parte dela.

Um caso análogo e mais próximo poderia ser o de Gregório de Matos, tal como apresentado por Haroldo de Campos em seu livro $O$ sequestro do Barroco na Formação da Literatura Brasileira, publicado originalmente em 1989, mas que retomava material esboçado por Haroldo ao menos desde 1978. É preciso ressaltar que o livro de Haroldo resgata a questão da oscilação entre cânone e exclusão a partir de, ao menos, duas camadas: em primeiro lugar, lida com a contraposição entre Barroco e Romantismo na historiografia literária brasileira, tomando como estudo de caso a posição de Gregório de Matos; em segundo lugar, lida também com o questionamento das premissas teóricas que Antonio Candido havia professado em 1959, com a publicação do estudo que é citado no título do livro de Haroldo de Campos.

Trata-se, portanto, de uma revisão do cânone literário brasileiro numa perspectiva histórica de longo alcance e, em paralelo, uma revisão do cânone crítico e historiográfico brasileiro tal como se apresentava em seu presente imediato. Esse jogo ganha atualização recente na reedição do livro de Haroldo, feita em 2011, que inclui como Apêndice um artigo, de 1996, no qual Haroldo de Campos retoma suas principais ideias a respeito de Gregório de Matos. No texto de orelha, Leda Tenório da Motta fala de um "silêncio constrangido" com relação a $O$ sequestro do Barroco nos últimos anos. A reedição de 2011, portanto, evoca não apenas o texto de Antonio Candido de 1959, mas também a argumentação apresentada por Haroldo de Campos em 1989 e a sedimentação que esse confronto sofreu nos vinte anos seguintes.

Da vasta exposição de Haroldo de Campos, interessa reter sua abordagem da história literária como entidade aberta e sua concepção do cânone como organismo plural, feito de atravessamentos e reciprocidades. O autor argumenta que, mesmo antes da publicação da Formação da literatura brasileira, de Antonio Candido, em 1959, e certamente nos anos

\begin{tabular}{|c|c|c|c|}
\hline EM & BELO HORIZONTE & v. 19 & N. 2 \\
\hline
\end{tabular}

\section{Ensino e teoria}


8. CAMPOS. O sequestro do Barroco na Formação da Literatura Brasileira: o caso Gregório de Matos, p. 67-72. imediatamente subsequentes, houve, na América Latina, um intenso esforço teórico de leitura das potencialidades do período Barroco e de seus principais artífices. Como membros desse esforço, Haroldo de Campos cita nomes os mais variados, desde Octavio Paz, Severo Sarduy e Lezama Lima até Walter Benjamin, Oswald de Andrade e Mário Faustino ${ }^{8}$. O que faz do livro de Haroldo de Campos um estudo recente é precisamente sua percepção, ainda atual e produtiva, de que para cada elemento tomado como canônico existe um suplemento que o contradiz e desafia, e essa presença contraditória diz respeito não apenas à obra ou autor em questão, mas também ao crítico de estabelece tal cenário canônico. Por isso que o livro de Haroldo de Campos é, simultaneamente, uma revisão de Gregório de Matos e de Antonio Candido.

Tendo em mente essa dinâmica entre o elemento canô nico e seu suplemento contraditório, que é a solução muito bem urdida por Haroldo de Campos do impasse entre substituição e agregação, como apresentado mais acima, com essa dinâmica, portanto, em mente, é possível seguir em frente e resgatar um ensaio publicado por David Damrosch em 2006 No âmbito dos debates promovidos pela Associação Norteamericana de Literatura Comparada em 2004, seu tradicional "Report on the State of the Discipline", que resultou em um volume coletivo de ensaios intitulado A literatura comparada na era da globalização, Damrosch propõe uma reflexão sobre o cânone e seus movimentos recentes dentro dos estudos literários. O título de seu ensaio é "World Literature in a Postcanonical, Hypercanonical Age", e indica, até certo ponto, as preocupações do autor no que diz respeito à definição do cânone a partir da renovação de seus processos (o pós-canônico) e a partir da inflação ou exacerbamento de suas características tradicionais (o hiper-cânone) ${ }^{9}$.

No início de seu texto, Damrosch retoma o diagnóstico já feito por Jonathan Culler, ou seja, aquele que indica uma movimentação canônica que diz respeito não à substituição de autores ou obras, mas à renovação dos pressupostos teóricos, que são requisitados, no entanto, para o provimento de leituras alternativas de autores e obras já conhecidos. $\mathrm{O}$ exemplo dado por Culler é Shakespeare, e Damrosch prefere James Joyce - citando trabalhos com os títulos hipotéticos de Joyce Semicolonial ou Joyce Transnacional ${ }^{10}$. Para Damrosch, esse tipo de perspectiva é insuficiente, pois, ao invés de desbravar novos campos de pesquisa fazendo uso das novas ferramentas de leitura disponíveis no âmbito da teoria, prefere seccionar campos de pesquisa já densamente povoados, algo que, paradoxalmente, serve não para enfraquecer as posições canônicas tradicionais, e sim para fortalecê-las. De quebra, essa perspectiva também enfraquece as próprias novas ferramentas que estão sendo utilizadas em espaços antigos, pois dão a impressão, argumenta Damrosch, de que são apenas
9. DAMROSCH. “World Literature in a Postcanonical, Hypercanonical Age", p. 43-53.

\section{Ensino e teoria}


11. Ibidem, p. 44. A questão da metafórica e teórimo função presente no pensamento crítico das últimas décadas, sobretudo das ultimas décadas, sobretudo no que diz respeito à obra de Jacques Derrida, por exemplo. Um apanhado recente dessa conjuntura pode ser encontrado Autoimmunity", p. 208-225. aplicações passageiras diante de um documento cultural perene e inquebrantável (Shakespeare ou Joyce). Nesse sentido, é possível dizer que o tiro sai pela culatra - ou que o feitiço se volta contra o feiticeiro.

Essa seria, para Damrosch, a situação "pós-canônica”, que mantem muitas semelhanças com a era pós-industrial do capitalismo, na qual se observa a transição da produção de bens para o provimento de serviços, ou seja, um estágio de maior sutileza e imaterialidade na relação dos sujeitos com os objetos. Damrosch dá o exemplo dos carros, que não só não diminuíram em quantidade como aumentaram muito, investindo em diferenciais de luxo, de customização e de pessoalização do trato do usuário com a máquina. Em resumo, os produtos pós-industriais continuam funcionando como funcionavam na era industrial. Nesse ponto, David Damrosch agudiza e complexifica as reflexões já mencionadas de Andreas Huyssen a respeito da natureza apressada de parte dos resultados apresentados pelos estudos culturais norte-americanos, ligando-os a uma conjuntura econômica e social mais ampla. O pós-canônico se liga ao pós-industria na medida em que reitera um modo antigo de leitura crítica sob uma pretensa roupagem inovadora, que mascara as antigas táticas de exclusão dentro de um sistema de inclusão que se pretende emancipatório, mas que somente enfraquece as próprias bases, como em um organismo autoimune ${ }^{11}$.
Depois de detectar tal paradigma pós-canônico em operação, Damrosch propõe, ainda que indiretamente, algumas estratégias alternativas de trabalho com o cânone. Em primeiro lugar, Damrosch apresenta uma triangulação de critérios, algo que envolve a repartição do cânone em três perspectivas: o hipercânone, o contracânone e o cânone-sombra. É na dinâmica dessa triangulação que se dá, para Damrosch, a oscilação entre as táticas de inclusão e as táticas de exclusão no trabalho com o cânone. As obras hipercanônicas são aquelas estabelecidas e tradicionais, como as de Shakespeare e Joyce. As obras contracanônicas geralmente são representativas de vozes de contestação, vindas de grupos minoritários no interior de países expressivos, como os Estados Unidos, ou vindas de literaturas distantes geograficamente, como aquelas dos países do Leste Europeu. O aspecto contracanônico dessas obras é reforçado por aspectos como o distanciamento temporal e a raridade, possibilidade ou dificuldade dos processos tradutórios que permitem a absorção dessas obras na reflexão teórica sobre o cânone. É na rarefação desses elementos bloqueadores que o contracânone se transforma em cânone-sombra, que abriga aqueles elementos que não tiveram força para sustentar uma ascensão canônica. E Damrosch conclui sua exposição classificatória com uma metáfora provocativa: no cenário pós-canônico, assim como no pós-industrial, os mais ricos entre os ricos ficam ainda mais ricos ${ }^{12}$

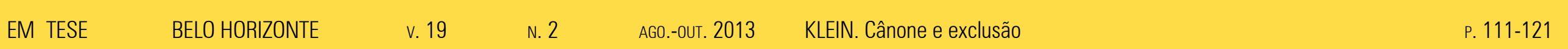

\section{Ensino e teoria}


Utilizando a base de dados da Modern Language Association, colhendo informações que vão de 1964 até 2003, Damrosch faz uma análise que leva em consideração os autores mais citados - que correspondem ao hipercânone - em contraste com aqueles que surgem, nos estudos, a partir da década de 1960, como contracanônicos (entre eles estão Toni Morrison, Salman Rushdie e Chinua Achebe) Damrosch chega à conclusão de que muitas vezes o contracanônico é utilizado como suporte para a defesa de leituras envolvendo o hipercanônico, mostrando que certas estratégias de inclusão funcionam como uma espécie de procedimento protocolar, como algo que garantiria, em tese, o pertencimento do trabalho a uma versão emancipatória dos estudos literários ou culturais. Não há o interesse, na perspectiva em questão, de promover uma passagem do contracanônico ao nível de visibilidade ou penetração do hipercanônico, e sim em fazer uso do contraponto entre um e outro como chancela para um pertencimento institucional ou disciplinar. É precisamente esse investimento frouxo nas potencialidades das obras contracanônicas que terminam por reforçar o hipercanônico e, além disso, com o passar das décadas, levar as primeiras em direção àquilo que Damrosch denomina de cânone-sombra ${ }^{13}$.

E Damrosch também menciona um aspecto complementar da relação entre cânone e exclusão: o acadêmico que se aventura excessivamente pelo contracanônico em seus textos corre o risco de não ser lido, compreendido ou seguido; e a mesma situação se repete em sala de aula, argumenta Damrosch, pois os estudantes apresentam resistência em acompanhar cursos ou projetos que envolvem escritores dos quais nunca ouviram falar ${ }^{14}$. É nesse ponto que Damrosch fala da necessidade de se elaborar uma relação entre hipercanônico e contracanônico que escape do protocolar, estabelecendo entre eles relações de reciprocidade e não de sucessividade - que é uma forma alternativa de trazer à tona aquilo que Andreas Huyssen chamou de horizontalidade no trato das referências. No modo vertical de conceber a relação entre hipercanônico e contracanônico, o último termo continua excluído do resultado final da equação, mesmo que incluído na superfície temática do trabalho. Algo desse paradoxo está presente na leitura que Haroldo de Campos faz da posição de Gregório de Matos na Formação da Literatura Brasileira de Antonio Candido, que apresenta a existência histórica do poeta barroco como uma não-existência em termos literários e "formativos"

No final de seu ensaio, Damrosch dá uma série de exemplos de como pode funcionar um trabalho de reciprocidade entre o hipercanônico e o contracanônico, todos eles envolvendo a obra de James Joyce. Tomando como ponto de partida um precursor comum, que é Henrik Ibsen, Damrosch
14. Ibidem, p. 50

15. CAMPOS. O sequestro do Barroco na Formação da Literatura Brasileira: o caso Gregório de Matos, p. 21-22.

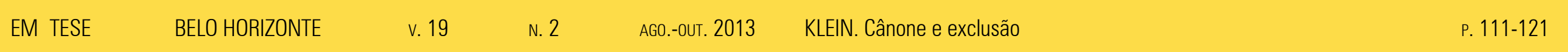

\section{Ensino e teoria}


16. DAMROSCH. “World Literature in a Postcanonical, Hypercanonical Age", p. 51.

17. Ibidem, p. 52.

18. Segundo Anna Klobucka, o ponto de partida da recepção de Clarice Lispector fora do Brasil se deu em 1978, quando Hélène Cixous descobriu a obra da escritora brasileira e iniciou não apenas sua tradução, mas também trabalho crítico de interpretação. Cf. KLOBUCKA. “Hélène Cixous and the Hour of Clarice Lispector", p. 41. propõe uma leitura de Joyce em contraste com sua contemporânea japonesa Higuchi Ichiyo. Os dois autores compartilham não apenas escolhas temáticas, mas também soluções técnicas como construção narrativa, uso de diálogos e de linguagem figurativa. Fazendo uso de um duplo referencia - a contemporaneidade e a leitura do mesmo precursor Damrosch horizontaliza o contato entre o hipercanônico Joyce e a contracanônica Ichiyo ${ }^{16}$. Em seguida, Damrosch parte para a possibilidade de comparar Joyce com seus sucessores, citando o caso de Clarice Lispector, que aponta como um dos autores mais importantes da segunda metade do século XX, tendo produzido uma das mais criativas apropriações de Dublinenses, o livro de contos de Joyce, em seu Laços de família ${ }^{17}$. Segundo as informações que Damrosch extrai da base de dados da Modern Language Association, o trabalho de comparação entre Joyce e Lispector já existe, mas é ainda muito limitado ${ }^{18}$.

A menção a Clarice Lispector feita por Damrosch pode servir de ensejo para uma última reflexão a respeito do cânone e da exclusão. Isso porque a menção à autora brasileira indica uma reivindicação contracanônica dentro de um espaço no qual James Joyce é hipercanônico, e não o inverso, como é o caso no cenário acadêmico brasileiro, no qual a posição de Lispector é hipercanônica. Os dados de Damrosch vão de 1964 a 2003, e apresentam um crescimento no número de trabalhos sobre Clarice Lispector a partir do final da década de 1970, mas um número muito escasso de aproximações dela com Joyce - são apenas três trabalhos. Em primeiro lugar, é preciso ressaltar que toda tática de intervenção sobre o cânone é e sempre será historicamente situada, e desse posicionamento específico no tempo e no espaço decorrerá a dimensão da exclusão ou da inclusão, ou, para usar os termos de Damrosch, as dimensões do hipercanônico e do contracanônico. Assim como não há uma formação essencial para o cânone, uma estrutura unívoca e trans-histórica que lhe dê sentido e coesão, o mesmo vale para as estratégias teóricas de intervenção, que não podem ser somente de exclusão ou somente de inclusão. Essa conclusão em prol da não-essencialidade do cânone e das táticas discursivas que movimenta não pode se sustentar por si só, ou seja, tal conclusão não é eficaz simplesmente por conta de sua enunciação, ela está diretamente ligada ao percurso que a tornou possível. Esse percurso, que agora se encerra, solicitou o cânone não para reiterar sua tradicional opacidade discriminatória, mas para experimentar com sua carga teórica estratégica e emancipatória.

\section{REFERÊNCIAS}

BLOOM, Harold. $\mathbf{O}$ cânone ocidental: os livros e a escola do tempo. Trad. Marcos Santarrita. Rio de Janeiro: Objetiva, 1995.
EM TESE
BELO HORIZONTE
V. 19
N. 2
AG0.-0UT. 2013 KLEIN. Cânone e exclusão
P. $111-12$

\section{Ensino e teoria}


CAMPOS, Haroldo de. 0 sequestro do Barroco na Formação da Literatura Brasileira: o caso Gregório de Matos. São Paulo: lluminuras, 2011.

CHOW, Rey. "In the Name of Comparative Literature". In: Comparative Literature in the Age of Multiculturalism. BERNHEIMER, Charles (ed.). Baltimore: Johns Hopkins University Press, 1994, p. 107-116.

CULLER, Jonathan. Teoria Literária: uma introdução. Trad. Sandra Vasconcelos. São Paulo: Beca, 1999.

DAMROSCH, David. "World Literature in a Postcanonical,

Hypercanonical Age". In: Comparative Literature in the Age of Globalization. SAUSSY, Haun (ed.). Baltimore: Johns Hopkins

University Press, 2006, p. 43-53.

GINZBURG, Jaime. "O valor estético: entre universalidade e exclusão". Alea, Programa de Pós-Graduação em Letras

Neolatinas, Faculdade de Letras, Universidade Federal do Rio de Janeiro. 2008, vol. 10, n. 1, p. 98-107.

HUYSSEN, Andreas. "Literatura e cultura no contexto global". In: Valores: Arte, Mercado, Política. MARQUES, R.; VILELA, L. H. (orgs.). Trad. Julio Jeha. Belo Horizonte: UFMG, 2002, p. 15-36.

KLOBUCKA, Anna. "Hélène Cixous and the Hour of Clarice

Lispector". University of Wisconsin Press, SubStance, v. 23, n. 1 Issue 73, p. 41-62, 1994

MILLER, J. Hillis. "Derrida's Politics of Autoimmunity". Wayne State University Press, Discourse, v. 30, n. 1 e 2, p. 208-225, 2008.
MORAES, Eliane Robert. "Os perigos da literatura: o 'caso Sade"'. In: Lições de Sade: ensaios sobre a imaginação libertina. São Paulo: Iluminuras, 2011, p. 149-156.

SPIVAK, Gayatri Chakravorty. Pode o subalterno falar?. Trad. Sandra Almeida, Marcos Feitosa e André Feitosa. Belo Horizonte: UFMG, 2010

\section{Ensino e teoria}

